\title{
Acontecimentos e memórias da Rede Puxirão de Povos e Comunidades Tradicionais do Paraná
}

Events and memories of the Rede Puxirão de Povos e Comunidades Tradicionais

do Paraná

Josiane Carine Wedig

\section{(2) OpenEdition}

\section{Journals}

Edição electrónica

URL: https://journals.openedition.org/aa/4968

DOI: 10.4000/aa.4968

ISSN: 2357-738X

Editora

Programa de Pós-Graduação em Antropologia Social (UnB)

Edição impressa

Paginação: 213-231

ISSN: 0102-4302

\section{Refêrencia eletrónica}

Josiane Carine Wedig, «Acontecimentos e memórias da Rede Puxirão de Povos e Comunidades

Tradicionais do Paraná», Anuário Antropológico [Online], v.45 n. 1 | 2020, posto online no dia 27 janeiro 2020, consultado o 24 julho 2022. URL: http://journals.openedition.org/aa/4968 ; DOI: https://doi.org/ 10.4000/aa. 4968

\section{(c) $($ ) $\odot \odot$}

Creative Commons - Atribuição-NãoComercial-SemDerivações 4.0 Internacional - CC BY-NC-ND 4.0 https://creativecommons.org/licenses/by-nc-nd/4.0/ 


\title{
Acontecimentos e memórias da Rede \\ Puxirão de Povos e Comunidades \\ Tradicionais do Paraná
}

\author{
Events and memories of the Rede Puxirão de Povos e Comunidades \\ Tradicionais do Paraná
}

DOI: https://doi.org/10.4000/aa.4968

Josiane Carine Wedig • Universidade Tecnológica Federal do Paraná - Brasil

Professora de Ciências Humanas e do Mestrado em Desenvolvimento Regional da Universidade Tecnológica Federal do Paraná. Líder do grupo de pesquisa Gênero, Juventude e Cartografias da Diferença. Doutora em Ciências Sociais pela Universidade Federal Rural do Rio de Janeiro, com doutorado-sanduíche na École des Hautes Études en Sciences Sociales.

Neste artigo traçamos a genealogia da Rede Puxirão de Povos e Comunidades Tradicionais do Paraná, que agrega oito segmentos: indígenas, faxinalenses, quilombolas, cipozeiros, pescadores artesanais, ilhéus, detentores de ofícios tradicionais e comunidades de terreiro. A pesquisa foi realizada entre os anos de 2012 e 2015, através de observação participante das reuniões, entrevistas semiestruturadas com diversos interlocutores, além da análise de documentos (atas de reuniões, cartas finais dos encontros, fascículos das cartografias sociais etc.) - que constituem o acervo de cada uma das organizações que compõem a Rede e as entidades apoiadoras. A partir das memórias e narrativas das lutas dos participantes, das formas de acionamento desse saber nas práticas e enunciações atuais dos segmentos, podemos visualizar suas formas de organização coletiva.

Povos e Comunidades Tradicionais. Rede Puxirão. Territórios e resistências
This paper aims to map the genealogy of the Rede Puxirão de Povos e Comunidades Tradicionais do Paraná, a network that connects eight social groups: indigenous, faxinalenses, quilombolas, cipozeiros, artisanal fishermen, islanders, holders of traditional crafts and terreiro communities. The research was conducted between 2012 and 2015, through participant observation of meetings and semi-structured interviews with various interlocutors, as well as document analysis (minutes of meetings, final letters of meetings, fascicles of social cartography, etc.) - which constitute the collection of each of the organizations that make up the Rede and the supporting NGOs. From their memories and narratives of the participants' struggles, the ways of activating this knowledge in the current practices and statements of the segments, it was possible to visualize their forms of struggle.

Traditional Peoples and Communities. Rede Puxirão. Territories and resistances. 


\section{A genealogia como possibilidade de análise}

Este movimento da Rede [Puxirão] está desde Foz do Iguaçu até os pescadores do Litoral e dos Cipozeiros de Serra Baixa em Santa Catarina [...].

(Dionísio, integrante da $\mathrm{CEMPO}^{1}$, entrevista, maio, 2013).

E o que é essa Rede Puxirão? É um movimento de povos e comunidades tradicionais do Paraná que estão articulados em rede. Não é mais uma organização, é um espaço onde nós, os povos tradicionais do Paraná, nos articulamos para buscar juntos nossos direitos. E quando os movimentos tradicionais estão fortes, a Rede também se torna forte. E ela, a Rede Puxirão, tem um objetivo maior, que é de nós nos conhecermos, de trocarmos experiências e, ao mesmo tempo, de nos articularmos para exigir os nossos direitos junto ao Estado e também propor políticas públicas.

(Hamilton, faxinalense, fala pública no II Encontro de Benzedeiras do Centro-Sul do Paraná, 2012).

Neste artigo, traçamos a genealogia da Rede Puxirão, que agrega oito segmentos: indígenas, faxinalenses, quilombolas, cipozeiros, pescadores artesanais, ilhéus, detentores de ofícios tradicionais (benzedeiras, curandeiros, remedieiros/ as etc.) e comunidades de terreiro - formas como localmente são nomeados cada um dos povos e comunidades tradicionais ${ }^{2}$ que compõem a Rede (Wedig, 2016) ${ }^{3}-$ apresentando uma série de acontecimentos que permitiram a sua constituição. Nosso interesse não é reconstituir um caminho, como se pudéssemos apontar para uma origem única e para uma continuidade histórica, mas buscar a descrição de acontecimentos em sua diversidade e dispersão.

Nesse sentido, fazer uma genealogia (Foucault, 1994a; 1994b) não quer dizer apenas buscar no passado os traços de acontecimentos singulares, mas é trazer também, para a análise, os acontecimentos atuais. Assim, reconstituímos as condições de seu aparecimento, a partir de múltiplos elementos. Uma análise genealógica reconstitui toda uma rede de alianças, de comunicações, de pontos de apoio, a partir da diversidade, da dispersão e do acaso dos começos. A genealogia, portanto, se opõe à unicidade da narrativa histórica e da busca das origens (Revel, 2009). Ao contrário, ela busca "localizar a singularidade dos acontecimentos, fora de qualquer finalidade monótona, lhes espreita lá onde eles são menos esperados” (Foucault, 1994a, p. 136), não buscando apenas no passado os traços dos acontecimentos singulares, mas colocando a questão dos acontecimentos atuais (Revel, 2009).

Através da perspectiva genealógica, interessou-nos seguir "os saberes locais descontínuos, desqualificados, não legítimos, contra a instância teórica unitária que pretende lhes filtrar, hierarquizar, ordenar, em nome de um conhecimento verdadeiro, em nome dos direitos de uma ciência que seria possuída por alguns”
1 Centro Missionário de Apoio

ao Campesinato Antonio

Tavares Pereira (CEMPO).

2 A definição de povos e comunidades tradicionais que perpassa este artigo, remete a grupos que foram classificados, pela lógica do Estado, etnocentricamente, como menos que humanos ("primitivos", "selvagens", "atrasados") e, portanto, o acesso à terra lhes foi negado. Nesse sentido, seus territórios foram se constituindo por processos de resistência e (r)existência. Os dos povos indígenas tiveram seus territórios apropriados pelo colonialismo e pelo genocídio. Os povos africanos, arrancados de seus territórios, foram escravizados, e após a abolição não tiveram reconhecida a legitimidade de acesso à terra pelo Estado. Além deles, um conjunto de povos, foram se constituindo na relação intensa com a terra e produzindo modos de vida diferenciados com os coletivos não humanos, opondo-se ao modelos de dicotomia e separação sociedade e natureza, que marca a modernidade/colonialidade. Nesse sentido, seus territórios são constituídos por processos de resistência frente ao avanço do colonialismo e da colonialidade do poder, do saber e do ser (Quijano, 2005). É fundamental também considerar a autodefinição e os fatores étnicos e identitários coletivos pelos quais se reconhecem e são reconhecidos esses povos (Almeida, 2010), além das suas relações específicas com a terra.

3 Este artigo é resultado do primeiro capítulo de minha tese de doutorado (Wedig, 2015), defendida em 2015, no Programa de Pós-Graduação de Ciências Sociais em Desenvolvimento, Agricultura e Sociedade, da Universidade Federal Rural do Rio de Janeiro (CPDA/UFRRJ), sob a orientação de Leonilde Servolo de Medeiros, com 
(Foucault, 1994b, p. 165). Desse modo, o método genealógico é uma tentativa de desassujeitamento dos saberes históricos, tornando-os capazes de lutar contra a ordem do discurso hegemônico. Para isso, partimos tanto das memórias coletivas - que permitem a reconstituição do histórico das lutas - como das trajetórias coletivas - que organizam as lutas atuais.

Propusemos, assim, seguir a Rede Puxirão, não de maneira linear, mas remetendo-nos à multiplicidade de acontecimentos que permitiram sua composição. Assumem importância os processos anteriores, em que os agentes sociais que a compõem estavam envolvidos em outros movimentos sociais e organizações, em formas cotidianas de resistência (Scott, 2002) que engendram, atualmente, as suas formas de ações coletivas.

Desse modo, pela genealogia, trazemos à tona os saberes locais, para a compreensão dos acontecimentos, visando "reconstituir os fios que os ligam e que fazem com que se engendrem, uns a partir dos outros" (Foucault, 1993, p. 6). Um elemento fundamental para traçar a genealogia dos grupos que se reconhecem e são reconhecidos como povos e comunidades tradicionais são os conflitos pela terra/território que têm ocorrido no Paraná ${ }^{4}$ através de ameaças e/ou ocorrências de perda de seus territórios. As lutas e resistência desses grupos nos permitem compreender as dinâmicas atuais de sua organização política como povos e comunidades tradicionais.

A Rede Puxirão se insere no contexto sociopolítico em que diversas organizações de povos e comunidades tradicionais foram criadas ou fortalecidas no país, tendo como centralidade as reivindicações pelo reconhecimento territorial e dos modos de vida de grupos que foram historicamente estigmatizados ou desconsiderados pelas formas oficiais de regularização fundiária (Little, 2002; Almeida; Farias Junior, 2013).

Conforme Little (2006), o conceito de povos e comunidades tradicionais data das últimas décadas e está associado aos movimentos ambientalistas e dos direitos étnicos. No Brasil, as políticas públicas a eles associadas levam em conta um conjunto de elementos, como: o uso sustentável da terra; a produção utilizada para a realização das práticas sociais, autoconsumo e venda de excedentes; vínculo territorial específico ligado à memória coletiva; a situação fundiária ligada à posse ou propriedade com titulação coletiva ou situações de expropriação; organização social marcada por relações de família extensa e comunitárias; expressões culturais marcadas pela transmissão oral de conhecimentos; interrelação com outros grupos similares e autoidentificação pelo grupo e demais grupos e identificação formal pelo Estado.

\section{Acontecimentos que antecedem a composição da Rede Puxirão}

O acontecimento que marca a formação da Rede Puxirão de Povos e Comunidades Tradicionais do Paraná foi o encontro realizado no ano de 2008, quando alguns grupos passaram a se articular politicamente em torno da categoria de povos e comunidades tradicionais e a apresentar reivindicações para seu reconhecimento social e de seus territórios. Contudo, longe de se constituir em um financiamento do Conselho Nacional de Desenvolvimento Científico e Tecnológico (CNPq) e da Fundação Carlos Chagas Filho de Amparo à Pesquisa do Estado do Rio de Janeiro (FAPERJ)

4 O levantamento feito nos anos de 1980, denominado " 10 anos de luta pela terra: 1969-1979" (Medeiros, 1983), demonstra, a partir da análise dos arquivos da Confederação Nacional dos Trabalhadores na Agricultura (CONTAG) e da Comissão Pastoral da Terra (CPT) no Paraná, as denúncias que os camponeses encaminharam para os sindicatos e outras entidades sobre os conflitos fundiários e a luta pela terra. 
ato fundador, os ativistas ${ }^{5}$ da Rede Puxirão mencionam uma trajetória de lutas e resistências, de atividades de formação política e de articulação, cujo marco inicial da memória depende de quem narra.

Nesse sentido, a memória coletiva (Pollak, 1989; 1992) é fundamental para apreender as lutas do presente, pois ela se constitui como um conjunto de referências que compõem as narrativas sobre a composição da Rede Puxirão. Troillot (2016) aponta que o indivíduo só pode recordar o que se lhe revela de um evento, mas não o próprio evento, levando em consideração também que não existe passado independente do presente.

As narrativas e práticas dos ativistas possibilitam a construção de identidades coletivas a partir do reconhecimento mútuo (Scherer-Warren, 2008). No entanto, as identidades desses grupos não são fixas, mas sim permeadas pela constituição de "movimentos sociais mobilizados por identidades-em-devir, dessubstancializadas, diasporizadas" (Almeida, 2007, p. 174).

No que tange às narrativas dos ativistas dos segmentos da Rede Puxirão, normalmente, eles evocam o auxílio recebido por grupos inspirados na Teologia da Libertação ${ }^{6}$ em suas trajetórias de lutas. Frequentemente, são mencionadas as atividades realizadas por agentes ligados à Igreja Católica e Protestante que, desde os anos de 1970, desenvolviam cursos de formação política com os camponeses e que constituíram a Equipe de apoio na região Centro-Sul do Paraná - que agregava técnicos agrícolas, agrônomos, veterinários, camponeses, membros das igrejas - os quais se reuniam, periodicamente, para o encaminhamento de demandas. Sua criação se deu em um contexto de empobrecimento material, acompanhado de um intenso êxodo rural na região, no período em que se difundia no país a revolução verde (Goodman; Sorj; Wilkinson, 1990).

Nos anos de 1970, foi constituída, na região de Guarapuava, uma Equipe que passa a atuar com as/os camponesas (es), por meio de missionárias (os), com formação em agronomia e veterinária, vindos da Áustria, Holanda e Bélgica. A chegada delas (es) impulsionou a composição das primeiras associações e cooperativas de camponeses. Eles propuseram a organização da Pastoral Rural, que, posteriormente, se transformou em Comissão Pastoral da Terra (CPT), "que deveria cuidar, não só da espiritualidade [...] mas tinha como preocupação política fixar o pessoal no campo, para que não migrasse para a cidade" (Entrevista com Dionísio, integrante do CEMPO, maio 2013).

No Paraná, a CPT foi fundada no final da década de 1970, com foco na atuação do conflito gerado pela construção da hidrelétrica de Itaipu, que teve como consequência o alagamento de grande parte dos territórios tradicionais e que deslocou milhares de famílias atingidas. Posteriormente, seu trabalho se deu junto a camponeses, posseiros e trabalhadores rurais na luta pela reforma agrária. Alguns dos atuais ativistas da Rede Puxirão iniciaram suas atividades de militância na CPT ou, anteriormente, na Pastoral Rural. Como é expresso na fala de Hamilton, liderança faxinalense:
5 Utilizamos o termo ativistas para nos referirmos aos integrantes da Rede Puxirão, assinalando um engajamento permanente tanto nos espaços cotidianos como nos de organização política em que eles discutem e se mobilizam junto aos diversos segmentos (Wedig, 2016).

6 Corrente teológica cristã, cuja perspectiva de ação propõe a atuação frente aos contextos sociais concretos e que propiciou a formação de diversas pastorais, dentre elas, a CPT (Villalobos; Rossato, 1996). 
Eu iniciei a militância através da Pastoral, em 1983. E, através da Pastoral da Terra, a gente foi tomando conhecimento dos direitos do pequeno agricultor na época. E no município onde eu militava - onde eu comecei a militar na Pastoral - tinha e tem até hoje um conflito agrário com uma grande empresa latifundiária, que grilou as nossas terras e também as dos moradores que não eram faxinalenses, no meu município, que é o Pinhão. A Pastoral na época abraçou junto conosco essa causa e ali a gente começou a militar. [...] tem muita liderança que é fruto vindo da Pastoral e de alguns padres que ficaram no nosso município (Entrevista, novembro, 2013).

O apoio e a formação política realizada pela Igreja Católica, por intermédio da Pastoral da Terra, propiciaram que camponeses iniciassem sua trajetória de militância política em diversas organizações. Cabe salientar que a CPT regional, atualmente, não se dedica diretamente aos segmentos da Rede Puxirão em razão de um rompimento ocorrido em uma disputa por terra entre agricultores familiares e povos e comunidades tradicionais, mais precisamente, em um litígio de uma área de terra entre colonos e quilombolas, em que ocorreu a opção da CPT em apoiar os primeiros. No entanto, um grupo de pessoas que a integrava participa hoje do CEMPO, que é uma das principais Organizações Não Governamentais (ONGs) apoiadoras da Rede Puxirão.

A CPT do Paraná, segundo relatam os ativistas da Rede Puxirão, assumiu um papel central na organização das primeiras associações locais, dos sindicatos de trabalhadores rurais e de movimentos sociais estaduais e, mesmo, nacionais. A título de exemplo, a articulação da Equipe ligada à CPT, auxiliou a criação, em 1981, do Movimento dos Agricultores Sem Terra do Oeste do Paraná (MASTRO), formado por agricultores que foram expropriados pela construção da Usina Hidrelétrica de Itaipu - dentre eles os ilhéus (antigos moradores das ilhas do Rio Paraná) que compõem a Rede Puxirão - e que organizaram ocupações de terra na região, reivindicando o assentamento das famílias atingidas por essa construção.

A atuação da equipe da CPT e a experiência do MASTRO contribuíram para a fundação do Movimento dos Trabalhadores Rurais Sem Terra (MST), em 1984, na cidade de Cascavel/PR, "numa assembleia realizada no Centro Diocesano de Pastoral" (Entrevista com Dionísio, integrante da CEMPO, maio, 2013). Sobre essa relação entre a Equipe da CPT e o MST, Dionísio conta que

quando nasceu o MST, por alguns anos a Equipe, praticamente, usou todo o seu tempo somente com o pessoal do MST, na reforma agrária "convencional", com os que estavam sem terra e que tinham origem em alguma família de pequenos agricultores, onde o pai e a mãe tinham cinco hectares de terra e tinham sete ou oito filhos, então tinha muitos sem-terra em cada família (Entrevista, maio, 2013). 
Como relatam alguns ativistas, o que possibilitou a organização da Rede Puxirão está relacionado ao debate sobre reforma agrária feito nas reuniões da Equipe da CPT. O acompanhamento que a CPT fazia dos conflitos territoriais de comunidades negras, povos indígenas e outros produziram discussões sobre o modelo de reforma agrária que defendiam e que se diferenciava do modelo assumido pelo MST - principal movimento social que pautava a reforma agrária na região e no país - e que foi expresso nos seguintes termos: "[...] nós começamos a fazer essa reflexão: está ficando gente para trás que não pode ficar, que eram índios, quilombolas, faxinalenses, pescadores e ilhéus" (Entrevista com Dionísio, maio, 2013), cujas identidades estão permeadas por modos específicos de vivenciar os territórios. Observa-se que, nessa reflexão, está em curso uma concepção diferenciada de reforma agrária, que é "transfigurada em uma pluralidade de movimentos e de questões", trazendo consigo novos recortes da luta pela terra (Almeida, 2007, p. 180).

As questões territoriais colocadas por povos indígenas, comunidades negras, faxinalenses, entre outros, passaram a tensionar e ampliar aquilo que era concebido (na Equipe da Pastoral da Terra) como reforma agrária, à medida que as pautas de luta pela terra, para esses grupos, iam evidenciando modos singulares de ocupação, de uso, de vida e de relações com o território. A Equipe, mesmo atuando junto ao MST na região, passou a questionar os limites do modelo de reforma agrária defendido por esse movimento e a considerar as especificidades dos povos e comunidades tradicionais que lutavam pelo reconhecimento de seus territórios. Para esses grupos, não se tratava de lutar por alguma terra, fosse onde fosse, mas, sim, de batalhar pelo reconhecimento em espaços marcados por seus modos de vida.

Desse modo, o território, que designa os modos diferenciados de uso e ocupação da terra, passou a compor as bandeiras de luta pela permanência, retorno e demarcação dos seus espaços de vida. Sobre esses grupos, Almeida (2007) salienta que são dotados de particularidades linguísticas, religiosas, tecnológicas e sociais, com regras específicas de uso da terra. Para o autor, esses aspectos podem se constituir como elementos fundamentais para a reivindicação de direitos fundiários e outros.

As especificidades desses povos e comunidades tradicionais podem ser observadas no caso de Antônio Tavares, ativista da Rede Puxirão, antigo morador das ilhas do Rio Paraná, que foi atingido pela barragem de Itaipu no início dos anos 1980. Naquele período, ele passou a integrar o MST e desde então, participou das reuniões da Equipe. Mesmo depois de assentado, ele sempre se referia, nas reuniões, à vontade de voltar para as ilhas, "seu lugar", conforme ele e outros ativistas mencionam, suscitando a discussão sobre o território, como lugar em que a pessoa se "sente em casa".

Cabe mencionar que os segmentos que atualmente compõem a Rede Puxirão, anteriormente se reconheciam e realizavam suas lutas como trabalhadores rurais, pequenos agricultores, camponeses e participavam de organizações diversas: associações, sindicatos de trabalhadores rurais e outros movimentos sociais. 
Isso assinala que as identidades políticas vão sendo atualizadas e reformuladas, passando a assumir outros sentidos para os agentes sociais, mudanças que vão ocorrendo por meio dos contatos que esses estabelecem entre si, com outros grupos, nos processos políticos, sociais e culturais. Desse modo, o reconhecimento das especificidades socioculturais desses grupos e de suas formas de organização e de reivindicação territorial ocorrem nos processos de luta.

Em torno do reconhecimento do território, os grupos, como faxinalenses, ilhéus, pescadores artesanais, cipozeiros e outros, vão constituindo organizações próprias e agregando-se a outras cujas lutas são mais antigas (como os povos indígenas e as comunidades negras). Esses grupos salientam diferenças e singularidades políticas em relação a outras organizações camponesas das quais participavam anteriormente (ou que ainda participam) e que foram fundamentais nos processos de luta.

\section{A Rede Puxirão e suas teias de relações}

A Rede Puxirão é construída como "um movimento de povos e comunidades tradicionais do Paraná que estão articulados em rede", conforme consta numa das falas que abrem este artigo. É, portanto, um espaço de encontro de pessoas e de construção de apoio mútuo, permeada por continuidades e descontinuidades, agregações e rompimentos. O I Encontro de Povos e Comunidades Tradicionais do Paraná, realizado em Guarapuava, no ano de 2008, no qual foi constituída a Rede Puxirão, emergiu de um conjunto de experiências de lutas anteriores.

Igualmente, as experiências de outras organizações de povos e comunidades tradicionais no país deram impulso para essa organização. As ações realizadas por grupos e entidades apoiadoras criaram possibilidades de aproximação de grupos que passam a se reconhecer e ser reconhecidos como povos e comunidades tradicionais - por meio da articulação de suas lutas, especialmente, no que concerne à demanda pelos seus territórios - e a construir pautas comuns.

Esse Encontro foi proposto por três segmentos do Paraná que já estavam organizados em associações locais/regionais específicas e que participavam das reuniões da Equipe: os faxinalenses (da Articulação Puxirão dos Faxinalenses ${ }^{7}$ ), os quilombolas (da Coordenação Geral da Comunidade Invernada Paiol de Telha ${ }^{8}$ ) e os ilhéus (da Associação dos Atingidos pelo Parque Nacional da Ilha Grande ${ }^{9}$ ), conforme explica Tavares:

Então se juntaram naquela época quilombolas, faxinalenses e ilhéus, os três segmentos de origem. Aí começamos a discutir: qual é a luta dos faxinalenses? É os faxinais, a terra, o território. E a dos ilhéus? As ilhas, o território, a terra, a água e o espaço de vida. E a dos quilombolas? Também a terra e o território. Aí que a gente se deu conta de que a nossa luta é unificada, é tudo por terra, território, direitos, contra a exclusão social e as limitações colocadas por órgãos públicos que proíbem a gente de viver nos nossos territórios e dizem que somos criminosos quando retornamos e tentamos exercer a atividade de agricultura e pesca. Ainda vamos para a cadeia, porque se você
7 Sobre o histórico de organização política dos faxinalenses, conferir Souza (2010), Bertussi (2010) e Almeida e Souza (2009) 8 Sobre a resistência e organização política dos quilombolas do Paiol de Telha, conferir Hartung (2004).

9 Ver as histórias de vida sistematizadas no fascículo da Nova Cartografia Social dos Ilhéus do Rio Paraná (2009) 
corta uma árvore, uma madeira para fazer um barraco, uma casa, uma canoa ou o que não está no código florestal, não pode, vai punido, vai preso. Tem tudo isso. Então o que a gente fez? Vamos criar, vamos juntar! Nós lembramos que tem os ciganos, tem os indígenas, é o que nós sabíamos naquela época. Então vamos tentar. Procuramos esse povo e marcamos o primeiro encontro de povos e comunidades tradicionais. Marcamos o primeiro encontro. Deu ilhéus, quilombolas, faxinalenses, indígenas, veio os pescadores e cipozeiros. Seis segmentos naquela época. Esses seis segmentos deram origem, o início da Rede Puxirão (Tavares, ilhéu, entrevista novembro de 2014).

Sobre a formação da Rede Puxirão, também explica Hamilton:

[...] devido a esse conhecimento [da existência de outros grupos que vinham se organizando em nível nacional] e o de pesquisadores que nos ajudaram aqui no Paraná, começamos a discutir como é que a gente podia se articular em rede. E, em 2008, nós, em três segmentos - faxinalenses, ilhéus e quilombolas - discutimos a criação da Rede Puxirão. E fizemos o primeiro Encontro da Rede Puxirão, no estado do Paraná, que foi em Guarapuava, e chamamos para participar, todos os segmentos tradicionais do Paraná, mas puxada por esses três segmentos. Todos os segmentos tradicionais do Paraná vieram para esse Encontro e ali nasceu a Rede (Hamilton, faxinalense, entrevista, novembro 2013).

Participaram do Encontro, indígenas (Xetá, Guarani e Kaingang), cipozeiros, faxinalenses, quilombolas, pescadores artesanais e ilhéus, cujas reivindicações iniciais se pautaram pela garantia do acesso e/ou permanência em seus territórios históricos e tradicionalmente ocupados. É a partir desse Encontro que os grupos participantes, que provinham de organizações, associações e movimentos sociais diversos, oriundos do Paraná e do litoral de Santa Catarina ${ }^{10}$, decidem organizar a Rede Puxirão dos Povos e Comunidades Tradicionais do Paraná, o que passou a ser referido pelos ativistas como o acontecimento fundador. Ainda sobre essa formação, explica Dionísio:

No início a gente nem sabia se ia ser rede, a gente pensou: é bom que o pessoal se aproxime, crie uma liderança própria. Essa era um pouco a ideia. Foi amadurecendo e a gente disse: pode ser uma rede, como tinha outras redes, pode ser uma Rede de Povos e Comunidades Tradicionais (Entrevista, maio de 2013).

A Rede Puxirão foi constituída integrando ativistas de cada um dos grupos presentes no I Encontro, os quais passaram a se reunir bimestralmente, discutindo e encaminhando pautas específicas dos grupos, estabelecendo conexões entre suas pautas de reivindicações, articulando-se entre si e com outros movimentos
10 O fato de a Rede Puxirão ser nomeada como do Paraná não quer dizer que os segmentos que a compõem fiquem restritos à divisão das fronteiras político-administrativas do estado. Na maioria dos casos, percebemos que os territórios desses grupos transpõem fronteiras de países vizinhos (como o Paraguai e a Argentina), em cujas dinâmicas territoriais estão inseridos. 
sociais camponeses do Paraná. Ela passa a ser um espaço de articulação, tendo como objetivo o fortalecimento mútuo e político, buscando a efetivação de direitos étnicos e coletivos dos segmentos (Relatório Final do I Encontro, 2008). Na carta final desse I Encontro, os povos denunciam as violências a que estão submetidos, decorrentes do avanço das monoculturas, da criação de parques de preservação ambiental sobre seus territórios e reivindicam o seu reconhecimento e o de seus territórios.

Os grupos que formam a Rede Puxirão têm origens diversas. A maioria está constituída por associações, outros se reúnem sem ter uma organização formal e atuam em torno de conflitos e questões específicas. Ao mesmo tempo, na Rede Puxirão, são estabelecidas relações de apoio mútuo em ações políticas conjuntas, o que envolve, entre outras coisas, o encaminhamento de demandas reivindicativas para o Estado. Nesse espaço, em que esses grupos experienciam a inter-relação e o (re)conhecimento, buscam construir a cooperação entre os segmentos para a realização de suas ações políticas coletivas.

As pautas centrais na ação coletiva e pública dos segmentos são construídas pelos "vínculos de proximidade" (Cefaï; Veiga; Mota, 2011), que remetem àquilo que é vivido como tendo importância e pertinência na vida cotidiana dos ativistas, com ênfase nas situações problemáticas com que esses se defrontam. São, portanto, os vínculos territoriais, as histórias locais, as memórias coletivas e os conflitos que enfrentam que constituem os elementos que impulsionam sua organização política. No entanto, cabe salientar que essas questões locais são também globais, pois dizem respeito ao acesso à terra, às florestas, aos rios e mares e aqueles que as disputam - povos e comunidades tradicionais, as agências do Estado, os latifúndios e as megaempresas (Almeida, 2007).

Nas conexões que são estabelecidas entre os povos e comunidades tradicionais, diversos elementos e objetos que compõem seus modos de vida e seu cotidiano são mobilizados e vão encadeando alianças e articulando engajamentos na luta política, tanto nos seus encontros como em outras mobilizações políticas. Um exemplo desses elementos é o porongo ${ }^{11}$ (também conhecido como cabaça, planta de fruto oco e de casca dura), que se tornou o símbolo articulador da Rede Puxirão. Conforme expressa Tavares, ilhéu:

[...] e aí chegamos em um porongo ou purungo, que leva água para roça, um purungo que leva água para a caminhada, para a viagem e é da natureza, se cria na natureza. O porongo é típico da natureza, é ecológico e todo mundo usa, para tirar a sujeira da guarapa, para fazer rapadura, para guardar banha de porco, utiliza para um punhado de coisa. Para cuia, enfim. E foi usado o purungo como símbolo [da Rede Puxirão] (Entrevista, novembro de 2014).

A escolha do porongo ocorreu por ser utilizado pelos diversos segmentos tradicionais da região em seu cotidiano: como recipiente para guardar alimentos e bebidas, como instrumento musical (também usado nas celebrações religiosas afro-brasileiras), por seus atributos medicinais, por seu uso como cuia nas rodas
11 Planta do gênero Lagenária. É usada por diferentes grupos em diversas partes do país e conhecida como cabaça, cuia, porongo, coité ou cuité. 
de chimarrão e tererê (bebidas de origem indígena), como maraca, chocalho usado nos rituais xamânicos, etc. Nesse sentido, podemos considerar o porongo como um catalisador das alianças entre os segmentos, uma vez que é usado por todos eles, mas assume formas singulares de uso para cada um deles. Essa relação com o porongo pode ser relacionada à maneira como a Rede Puxirão se organiza, por exemplo, em sua luta pelo território, que é uma pauta comum, mas que assume formas diferentes para cada um dos segmentos.

O principal meio de divulgação pública das ações da Rede Puxirão é um blog ${ }^{12}$ (que é mantido por integrantes das ONGs apoiadoras: Instituto Equipe de Educadores Populares - IEEP e CEMPO) que divulga atividades que ocorrerão e relatos sobre as que foram realizadas, além de uma série de informações relacionadas aos segmentos. Contudo, essas divulgações não abrangem a totalidade das atividades da Rede Puxirão e dependem, fundamentalmente, da disponibilidade de alguém que maneje esses recursos técnicos. O blog é um instrumento de divulgação externo, que se constitui, principalmente, como um meio de informação e diálogo com os apoiadores (acadêmicos, ONGs etc.) e as autoridades públicas. Já entre os ativistas dos segmentos, o principal meio de contato e informação é o telefone e as visitas pessoais que esses realizam entre si.

Em folders e outros materiais de divulgação da Rede Puxirão são apresentados os números estimados de pessoas que compõem cada um dos segmentos. Esses levantamentos foram realizados por ativistas desses segmentos e por entidades apoiadoras, como as universidades, em razão da inexistência de estatísticas e censos oficiais sobre sua presença no Paraná. Foram identificados também os conflitos e ameaças em que cada um dos segmentos está envolvido. A junção dessas informações foi facilitada pela construção das cartografias sociais, que têm auxiliado na identificação dos povos e comunidades tradicionais no estado. Os números reunidos nos levantamentos de 2010 são os seguintes: 30.000 indígenas, 40.000 faxinalenses, 20.000 quilombolas, 7.000 cipozeiros, 12.000 pescadores artesanais, 7.000 detentores de ofícios tradicionais (benzedeiras e curandeiros), 70.000 integrantes de comunidades de terreiro.

É importante referir que as pessoas que compõem cada um desses segmentos podem integrar, simultaneamente, mais de um deles. Por exemplo, no grupo de detentores de ofícios tradicionais, há pessoas que são também faxinalenses ou indígenas, e assim por diante. São, portanto, números relativos e não absolutos (e nem pretendem sê-lo). Além disso, é significativo observar que essa contagem não expõe o número de pessoas organizadas coletivamente em torno de identidades políticas, mas se refere ao número de pessoas que compõem grupos com modos de vida específicos e com os quais a articulação política, para a participação coletiva, pode vir a ocorrer. Apresentar esses números é uma forma da Rede Puxirão chamar atenção do Estado e da sociedade em geral, sobre a existência desses povos na região e da necessidade de seu reconhecimento e da criação de políticas públicas específicas, que levem em conta as singularidades de seus modos de vida. 


\section{As reuniões como espaços de construção da luta pelos segmentos}

Os principais espaços de articulação na Rede Puxirão são as reuniões, nas quais se dá o debate coletivo e são construídas pautas conjuntas, a partir do reconhecimento da legitimidade das demandas e das especificidades de cada um dos segmentos. São espaços de experimentação e de coaprendizagem. Ao reunir segmentos com trajetórias diversas de luta, a Rede Puxirão se constitui como um espaço de troca de conhecimentos e de informações, de formulação de denúncias e de reivindicações coletivas, fundamentalmente pela questão dos territórios.

Nesses encontros geram-se vínculos que produzem as dinâmicas de organização, reivindicação e mobilização coletiva, através de diálogos entre agentes diversos, que passam a compartilhar suas experiências. É a partir desses conhecimentos compartilhados que os segmentos concebem a possibilidade de ação política conjunta. A fala de Dimas (um ativista faxinalense), em uma das reuniões da Rede Puxirão, expressa essa dimensão:

É importante o segmento apresentar como está o planejamento do movimento. [A reunião] é um momento de socializar [...]. A Rede é um espaço em que a gente socializa as lutas, pega o que é comum entre os segmentos e o que dá para a gente pegar junto na ação coletiva para ganhar mais força para encaminhar essas demandas. Mas é importante saber também como estão as ações [de cada segmento], aí no repasse de cada segmento começa a identificar [as possibilidades de atuação conjunta] (Fala pública na reunião de março, 2013).

Os segmentos, nesses espaços, trocam experiências, relatam e denunciam os conflitos, debatem e encaminham ações conjuntas. Eles colocam em relação diferentes perspectivas e modos de vida. A própria ação coletiva, enquanto Rede Puxirão, depende dessa relação intensiva de alteridade. Portanto, esse modo de fazer política coloca mundos diferentes em relação.

Quando se reúnem coletivamente, os ativistas dos segmentos relatam os conflitos existentes e os enfrentamentos que fazem contra os poderes econômicos e políticos - latifundiários, empresários, governos e representantes de órgãos públicos. Mencionam situações de conflitos diversas: o avanço das monoculturas de pínus, eucalipto, soja, fumo e outros; as grilagens de suas terras; o mercado de terras (impulsionado pelo agronegócio e pelos empreendimentos de lazer nas áreas rurais); as grandes obras de infraestrutura (como as usinas hidrelétricas ${ }^{13}$ ); a criação de áreas de preservação ambiental (nas quais tem sido desconsiderada a presença desses grupos e que leva a sua expulsão pelos fiscais dos órgãos ambientais). Denunciam ainda os assassinatos de integrantes dos segmentos, as derrubadas dos marcos que delimitam seus territórios e o avanço sobre esses, a destruição das suas roças e plantações, o envenenamento da água e da terra por agrotóxicos, o impedimento do acesso às águas e às florestas, ao mato, a falta de oferta dos serviços públicos de saúde, educação etc. Essas circunstâncias todas são expressas na fala de Acir Túlio (liderança faxinalense):
13 Os conflitos relacionados a esses empreendimentos na região iniciaram-se com a construção de Itaipu, na década de 1970 e avançaram com a construção de barragens em outros rios do Paraná. 
Essa é uma das angústias nossas, dos faxinalenses. Estão envenenando as águas e com isso envenenam os animais e os próprios alimentos. Nós faxinalenses estamos cansados já de bater na porta lá do IAP [Instituto Ambiental do Paraná]. Então isso para nós é muito triste, você vê um animal bebendo água envenenada, é mato destocado e gente desmatando dentro do faxinal e fora do faxinal e eles não estão fazendo nada. Então eu acho assim, é uma luta nossa e a gente está pensando em fazer um manifesto e ocupar o IAP. Porque uma vez nós fomos em 200 ou 300 pessoas lá, ocupamos o IAP e eles atenderam e agora está continuando do mesmo jeito (Fala pública na reunião da Rede Puxirão em março, 2013).

As reuniões são espaços de socialização das lutas e de construção de ações políticas coletivas, um progressivo "pensar junto" (Pimentel, 2012) ${ }^{14}$ tanto para o enfrentamento de antagonistas e resolução de conflitos quanto para os encaminhamentos de suas pautas ao Estado. A partir das narrativas dos ativistas, podemos perceber que as lutas desses segmentos, na defesa de seus territórios, ocorrem há gerações, por meio das formas cotidianas de resistências (Scott, 2002), que permitiram a continuidade de seus modos de vida. No entanto, nos últimos anos, suas lutas têm adquirido maior visibilidade pública, a partir da ação coletiva, com demandas dirigidas para o Estado, em um contexto em que dispõem também de parâmetros jurídicos e administrativos de políticas públicas especiais voltadas para povos e comunidades tradicionais no país.

Em suas falas trazem à tona memórias individuais e coletivas, trajetórias familiares e dos grupos, em que são identificados os agentes em luta, o lugar em que essas disputas ocorrem, contra quem, com quais instrumentos elas são e foram feitas e quais as questões que perpassam os enfrentamentos. Observa-se, assim, que os segmentos estão inseridos em diferentes conflitos e realizam diversas formas de luta - enfrentamentos diretos e cotidianos, denúncias judiciais, passeatas, acampamentos etc.

Nas reuniões, articulam-se discursos, práticas e visões dos ativistas, ocorrendo a interação entre pontos de vista muito diversos entre si, os quais, contudo, não visam constituir uma síntese unificada, nem a instituição de um modo uniforme de ação ou de unificação das diferenças. O que ocorre são conexões, cruzamentos, constituídos por processos de junção e disjunção, em que as diferenças, as demandas e lutas dos segmentos são perpassadas, afetadas e transformadas pelas relações entre os ativistas.

Quando a Rede Puxirão é enunciada como espaço no qual "nós nos conhecemos, trocamos experiências e nos articulamos" -, como é salientado na fala que abre este artigo e também na de outros ativistas - percebe-se que a prática da alteridade que ali se opera, em que se dá a relação entre as diferenças, cria a possibilidade de alianças para a ação coletiva. Os vínculos entre as diferenças (modos de vida e formas de luta) geram a desestabilização de formas de organização política pré-definidas e estabelecem um caráter inventivo das ações coletivas. São justamente as diferenças e as singularidades que se cruzam nos espaços de
14 É interessante observar as aproximações entre a forma das reuniões da Rede Puxirão e as Aty Guasu (assembleias indígenas) analisadas por Pimentel (2012) entre os Guarani e Kaiowá no Mato Grosso do Sul. Não nos detivemos aqui em traçar relações, mas esse é um tema que consideramos fundamental para a compreensão de algumas dinâmicas específicas das formas de interação política entre os povos e comunidades tradicionais e o aprendizado que se obtém com as organizações indígenas. 
reunião que permitem as ações coletivas entre os segmentos.

É nesses espaços das reuniões e dos encontros que ocorre a relação política, em que se constroem - ou mesmo se rompem - vínculos sociais, políticos, interindividuais e interorganizacionais. As relações políticas e alianças entre os segmentos fazem-se e refazem-se a todo momento, em razão de conflitos, alianças, movimentações (Pimentel, 2012). Neles se produzem mensagens de conexão e de mobilização, desenvolvem-se as pautas políticas em torno de necessidades e de noções de direito e justiça dos grupos, ao mesmo tempo em que se conectam espaços locais, regionais, nacionais e internacionais (Scherer-Warren, 2008), através da circulação de pessoas, de debates, de reivindicações, de leis, de símbolos, de projetos etc.

São pontos de vista diversos que se põem em diálogo nas reuniões da Rede Puxirão. Esse diálogo não se constitui apenas por um "respeito da opinião do outro", mas, sim, pelas relações em que se consideram importantes as divergências, em que a construção da ação coletiva ocorre pela articulação com saberes divergentes, produzindo o que Stengers (2013) definiu como fazer pensar, fazer hesitar juntos aqueles e aquelas que se reúnem.

As reuniões da Rede Puxirão ocorrem bimestralmente, em Guarapuava/PR, tanto no espaço da Fundação para o Desenvolvimento Econômico Rural da Região Centro Oeste do Paraná (RURECO) ${ }^{15}$ como no Centro de Formação Indígena Juan Diego e agregam ativistas de diferentes grupos locais/regionais, das entidades que compõem atualmente a Equipe, anteriormente ligada à CPT: os "movimentos sociais históricos", como o MST, o Movimento dos Pequenos Agricultores (MPA), o Movimento de Atingidos por Barragens (MAB), os agricultores ecologistas ${ }^{16}$, os segmentos que compõem a Rede Puxirão e as ONGs apoiadoras (CEMPO e IEEP). Também participam pesquisadoras de diversas universidades.

A participação dos membros dos segmentos nas reuniões é proporcionada pela mediação financeira da CEMPO, que tem arrecadado recursos de instituições nacionais e internacionais para pagar o transporte e a hospedagem dos ativistas. A alimentação fica por conta dos segmentos e é proveniente das suas comunidades e partilhada, entre todos os participantes, durante os dias de encontro.

As reuniões ocorrem, normalmente, durante dois ou três dias. As atividades são divididas da seguinte forma: primeiramente, é realizada a apresentação de todos os presentes e de suas respectivas organizações. Após, é realizada a mística, com leitura de uma passagem bíblica e com reflexões coletivas sobre as relações entre essas histórias e a situação atual dos povos e comunidades tradicionais. São traçados paralelos e estabelecidas correspondências entre as narrativas bíblicas - do povo que era explorado, que busca a terra prometida - e a situação dos camponeses e dos povos e comunidades tradicionais na atualidade. Aproximam-se, portanto, as histórias bíblicas do sofrimento e exploração do povo com as memórias de povos e comunidades tradicionais, permeadas por formas de exclusão e de discriminação. São feitas referências a vivências semelhantes, tanto no que concerne à opressão quanto às resistências, em que se considera a continuidade da luta do povo.
15 A Fundação RURECO é uma organização não governamental situada no interior do município de Guarapuava, estado do Paraná, fundada em 1986, a partir da organização de agricultores familiares, com o apoio da Pastoral da Terra e de Sindicatos de Trabalhadores Rurais. Foi criada com o objetivo de "apoiar e articular regionalmente as ações das organizações dos pequenos agricultores nas áreas de produção, beneficiamento, comercialização e do associativismo". Para o início do trabalho, a RURECO contou com o financiamento de agências internacionais da Alemanha, Holanda e Bélgica (FUNDAÇÃO RURECO. Disponível em: http:// www.rureco.org.br/main. php?page=front. Acesso em: 22 mar. 2013.

16 Os agricultores ecologistas são aqueles que militam pela agroecologia e têm se organizado politicamente para reivindicar acesso a políticas públicas de incentivo à produção e comercialização. Eles também fazem parte de outros movimentos sociais e de povos e comunidades tradicionais. 
A bíblia acionada para a mística é católica, mesmo que haja inúmeras diferenças religiosas entre os participantes. Essa prática é justificada nas reuniões por meio da afirmação de que "a Equipe teve origem no mundo católico", da perspectiva da Teologia da Libertação, fomentada pela CPT - que anteriormente acompanhou a organização e o trabalho das famílias camponesas na região e que atualmente se propaga com a atuação da CEMPO. É salientado o ecumenismo das reuniões e das ações. Faz-se, frequentemente, referência a Jesus, que defendia uma "outra proposta para a sociedade", um projeto de justiça social e de solidariedade, posicionado junto do povo, ao lado dos pobres, compadecido com sua luta.

No salão em que ocorrem as atividades conjuntas, as cadeiras são dispostas em círculo e, ao centro desse, encontram-se no chão: um banner exibindo a imagem do Monge João Maria (referência religiosa da luta pela terra na região, ligado à Guerra do Contestado, 1912-1916), as bandeiras do MST, do MAB, do MPA, do Movimento de Mulheres Agricultoras do Paraná e dos Povos Faxinalenses, os fascículos da cartografia social (realizadas com diversos segmentos da Rede Puxirão), ervas medicinais, cestos confeccionados pelos povos indígenas, o porongo (símbolo da Rede Puxirão), uma bíblia, entre outros elementos.

As bandeiras e objetos dispostos no centro da sala variam um pouco de uma reunião para outra, dependendo dos grupos que se fazem presentes e dos objetos aportados pelos participantes. Essa composição de objetos, oriundos dos diversos segmentos, enuncia aspectos políticos, territoriais e identitários, sinalizando para a forma como as diferenças podem se conectar em suas ações coletivas. A presença dessa multiplicidade de elementos sinaliza para engajamentos que não se excluem, não são antagônicos e também não se unificam, mas realizam conexões e interações em rede.

Nas reuniões entoam-se canções que fazem menção à luta pela terra, a partir de um cancioneiro intitulado "Cantando com a mãe terra", que é distribuído entre os presentes e que foi elaborado pela CPT do Rio Grande do Sul para a Via Campesina. O uso de cantos e gritos de luta comuns àqueles usados por outros movimentos camponeses sinaliza para as interações e aproximações realizadas pelos segmentos da Rede Puxirão, em uma espécie de aliança que se expressa, principalmente, pela tentativa de construção de uma linguagem e de símbolos partilhados, que são atualizados nas diferenças que os constituem.

Entre os códigos comuns, podemos citar que os ativistas da Rede Puxirão e dos demais movimentos sociais (pequenos agricultores/camponeses que participam do MST e do MPA e agricultores ecologistas) frequentemente evocam a "luta contra o agronegócio". Nesse sentido, mesmo que os ativistas reconheçam as diferenças entre os seus modos de vida e as formas de luta, eles estabelecem relações entre si, as quais operam um embate contra um "inimigo comum", que vai assumindo configurações diversas, desde os latifundiários da monocultura, mas também os responsáveis pelas grandes obras de infraestrutura e pelas sobreposições das áreas de preservação ambiental aos seus territórios. Os enfrentamentos se dão contra a transformação dos territórios em mercadoria, em interesses econômicos, sobrepostos aos seus modos de vida. 
Na primeira parte das reuniões, são abordados diversos temas, considerados comuns aos diferentes grupos que compõem o encontro, como a participação nos conselhos municipais, estaduais e federais; debates sobre agroecologia; discussões sobre representação política, sobre direitos e legislações específicas para camponeses e povos e comunidades tradicionais etc.

No segundo dia da reunião, as (os) participantes subdividem-se em três grupos: o dos "movimentos sociais históricos", o dos agricultores ecologistas e o dos segmentos da Rede Puxirão. É importante salientar que essas identidades políticas não são fixas e, muitas vezes, se cruzam e assumem multiplicidades de engajamentos. Por exemplo, um ilhéu pode ser, ao mesmo tempo, assentado da reforma agrária e reconhecido como camponês; um faxinalense pode ser também agricultor ecologista e assim por diante. Para a finalização dos dias de reuniões, novamente os três grupos se reúnem para partilhar suas decisões e encaminhamentos.

Nas reuniões das quais participamos, foi possível perceber que os faxinalenses e também os ilhéus participam em um número visivelmente maior e, em geral, são também os que mais fazem uso da palavra e que coordenam a maior parte da reunião. As benzedeiras e pescadores, mesmo sendo em menor número, sempre participam das reuniões. Os outros segmentos participam em algumas reuniões. Normalmente, as ausências são justificadas pelo excesso de demandas específicas dos segmentos, com pouco tempo para atuar também na Rede Puxirão.

Nesse sentido, observamos, como salienta Anjos (2006), que a participação ativa na política requer tempo livre para se realizarem reuniões, para se informar e, com isso, formar-se politicamente. Entre os ativistas da Rede Puxirão, alguns são "liberados" para participar e obtém ajuda financeira que lhes é fornecida pelos integrantes das associações locais e grupos que integram. Em outros segmentos, esses auxílios são mais restritos, o que provoca dificuldade de participação nas atividades, que são marcadas por algumas ausências.

A atuação dos ativistas da Rede Puxirão nos conselhos municipais, estaduais e nacionais é um assunto constantemente abordado nas reuniões. Eles os definem como espaços importantes para pautar direitos, nos quais se discutem temas relacionados à educação, alimentação escolar, saúde, segurança alimentar e nutricional, entre outros. Há também a discussão da participação específica no Conselho Estadual de Povos e Comunidades Tradicionais, cuja demanda de criação partiu da própria Rede Puxirão e que tem como pauta principal os direitos territoriais.

As reuniões da Rede Puxirão são consideradas pelos ativistas como importantes espaços de formação:

A gente debate, vai buscar gente que entende do assunto, dos amparos legais e da elaboração de propostas. Mas não é curso, é encontro que nós fazemos a cada dois meses, e ele se torna um momento de formação. Todo o encontro, toda a reunião, ela é de formação. [...] onde a gente aprende uns com os outros. Para uns, é chover no molhado [debater o que já sabemos], mas, para outros não, é coisa nova e está só aprendendo. E, com isso, es- 
tão vindo lideranças novas. Então, aquilo que eu passei há vinte anos, tem gente iniciando hoje (Entrevista Hamilton, novembro, 2013).

Os ativistas, normalmente, fazem relatos sobre a situação dos processos de reconhecimento de seus territórios e denunciam situações de violência e descaso do Estado. Pesquisadoras(es), advogadas(os) e representantes públicos são requisitados para prestar esclarecimentos sobre questões burocráticas e legais que afetam os territórios reivindicados, em razão das linguagens institucionais serem, muitas vezes, inacessíveis e se basearem em lógicas outras.

\section{Algumas considerações finais}

Ao realizar a genealogia das formas de luta, dos "saberes sujeitados", é possível fazer emergir os conteúdos históricos que foram sepultados, mascarados em coerências funcionais ou em sistematizações formais e, ao mesmo tempo, fazer eclodir aqueles saberes que estavam desqualificados como não conceituais, como insuficientemente elaborados, considerados como ingênuos, hierarquicamente inferiores. É, portanto, uma construção que se faz pelo reaparecimento desses saberes das pessoas, que não se constituem como comuns, mas como particulares, locais, regionais, diferenciais (Foucault, 1999).

Cabe salientar que a produção de narrativas históricas envolve a desigual contribuição de grupos e pessoas, que têm acesso desigual aos meios dessa produção (Trouillot, 2016, p. 58), ao mesmo tempo que "qualquer narrativa histórica é um conjunto específico de silêncios, o resultado de um processo singular, e a operação necessária para desconstruir estes silêncios variará de acordo com eles”. Esse é um aspecto que merece atenção pois, mesmo quando as vozes são de povos que foram subalternizados por silenciamentos de narrativas hegemônicas, ainda podemos perceber que, dentro dessas organizações, como no caso da Rede Puxirão, há um silenciamento maior de alguns sujeitos, por exemplo, das mulheres. Nesse sentido, a produção da própria pesquisa foi marcada pela criação de silêncios, pois acabou seguindo mais aqueles atores sociais estabelecidos enquanto lideranças.

Assim, quando eclodem essas memórias, há ainda camadas de silêncios de sujeitos que integram esses povos mas que não estão, necessariamente, nos espaços de debate coletivo. E mesmo aqueles e aquelas que participam desses espaços há menções ou silenciamentos de vários tipos e níveis, em que alguns acontecimentos são privilegiados em detrimento de outros, em que as instâncias de inclusão e exclusão implicam escolhas, questões para as quais nos chama atenção Trouillot (2016). Assim, os acontecimentos que permeiam a história da Rede Puxirão, que foram trazidos para este artigo apresentam algumas partes de seu processo constitutivo.

Em nosso contexto, esses saberes e memórias coletivas de lutas são expostos por lideranças de povos e comunidades tradicionais, envolvidos em uma série de conflitos fundiários, ligados à expulsão de seus territórios, à resistência contra inúmeras pressões para que os abandonem, às lutas pela relação ambiental específica, às reivindicações pelas passagens por territórios etc. Esses grupos, com 
inúmeras especificidades em seus modos de vida, passaram a se articular, criando redes de relações, conexões políticas, encadeamentos que perpassam diversas escalas (do âmbito local ao internacional), em que, além dos agentes que integram os segmentos, atuam também integrantes de ONGs, de universidades e outros.

Como vimos, as reuniões constituem o principal espaço de articulação da Rede Puxirão. É nesses encontros que se realiza a formação política, que se constroem as relações de alteridade, de conhecimento recíproco e de elaboração de planos de ação coletiva. É também onde ocorrem as discussões sobre as formas de ação, os questionamentos entre os segmentos e as ONGs apoiadoras. Frequentemente, discute-se o limite das intervenções dos ativistas de ONGs e mesmo das universidades com os segmentos.

Pudemos observar que a Rede Puxirão conecta grupos diferenciados, envolvidos em conflitos que assumem formas distintas, com reivindicações, demandas e encaminhamentos de luta singulares. No entanto, as questões que perpassam as falas de todos envolvem o reconhecimento dos territórios tradicionais e de seus modos de vida.

Recebido: $22 / 08 / 2019$

Aprovado: $30 / 10 / 2019$ 
Josiane Carine Wedig

\section{Referências}

ALMEIDA, Alfredo Wagner Berno de. Agroestratégias e desterritorialização - direitos territoriais e étnicos na mirados estrategistas dos agronegócios. In: ALMEIDA, Alfredo Wagner Berno de [et al.]. Capitalismo globalizado e recursos territoriais - fronteiras da acumulação no Brasil contemporâneo. Rio de Janeiro: Lamparina, 2010.

ALMEIDA, Alfredo Wagner Berno de; FARIAS JUNIOR, Emmanuel de Almeida (Org.). Povos e comunidades tradicionais: nova cartografia social. Manaus: UEA Edições, 2013.

ALMEIDA, Alfredo Wagner Berno de; SOUZA, Roberto Martins de Souza (Org.). Terras de faxinais. Manaus: UEA Edições, 2009.

ALMEIDA, Mauro William Barbosa de. Narrativas agrárias e a morte do campesinato. RURIS, v. 1, n. 2, p. 157-186, 2007.

ANJOS, José Carlos dos. No território da Linha Cruzada: a cosmopolítica afro-brasileira. Porto Alegre: Editora da UFRGS; Fundação Cultural Palmares, 2006.

BERTUSSI, Mayra Lafoz. Liberdade para criar: um estudo etnográfico sobre os sentidos da territorialidade tradicional e do criadouro comunitário em uma comunidade de Faxinal no Paraná. Dissertação (Mestrado em Antropologia Social) - Universidade Federal do Rio Grande do Sul, Porto Alegre, 2010.

CEFAÏ, Daniel; MELLO, Marco Antônio da Silva; MOTA, Fábio Reis; VEIGA, Felipe Berocan (Org.). Arenas públicas: por uma etnografia da vida associativa. Niterói: Editora da Universidade Federal Fluminense,2011.

FOUCAULT, Michel. Em defesa da sociedade: Curso do Colège de France 1975-1976. São Paulo: Martins Fontes, 1999.

FOUCAULT, Michel. Le jeu de Michel Foucault: entretien avec D. Colas et al., 1977. In: Dits et écrits. v. III. Paris: Gallimard, 1994b.

FOUCAULT, Michel. Microfísica do poder. São Paulo: Edições Graal, 1993.

FOUCAULT, Michel. Nietzsche, la généalogie, l'histoire. In: Dits et écrits. v. II. Paris: Gallimard, 1994a.

GOODMAN, David; SORJ, Bernardo; WILKINSON, John. Da lavoura às biotecnologias. Rio de Janeiro: Campus, 1990.

HARTUNG, Miriam Furtado. 0 sangue e o espírito dos antepassados: escravidão, herança e expropriação no grupo negro Invernada Paiol de Telha. Florianópolis: NUER/ UFSC, 2004.

LITTLE, Paul Elliott. Mapeamento conceitual e bibliográfico das comunidades tradicionais no Brasil. Brasília: Departamento de Antropologia da UnB, 2006.

LITTLE, Paul Elliott. Territórios sociais e povos tradicionais no Brasil: por uma antropologia da territorialidade. Brasília: Editora da UnB, 2002. (Série antropológica, 322).

MEDEIROS, Leonilde Servolo de. 10 anos de luta pela terra - 1969-1979. Rio de Janeiro: CEDEC/ABRA/CPDA/CONTAG/CPT, 1983.

NOVA CARTOGRAFIA SOCIAL DOS POVOS E COMUNIDADES TRADICIONAIS DO BRASIL. Ilhéus do Rio Paraná. v. 15. Guaíra: UEA Edições, 2009.

PIMENTEL, Spensy Kmitta. Elementos para uma teoria política Kaiowá e Guarani. Tese (Doutorado em Antropologia Social) - Universidade de São Paulo, São Paulo, 2012.

POLLAK, Michael. Memória e identidade social. Estudos Históricos. Rio de Janeiro, n. 5 , v. 10, p. 200-212, 1992. 
Josiane Carine Wedig

POLLAK, Michael. Memória, esquecimento e silêncio. Estudos Históricos. Rio de Janeiro, v. 2, n. 3, p. 3-15, 1989.

QUIJANO, Anibal. Colonialidade do poder, eurocentrismo e América Latina. Perspectivas latino-americanas. In: LANDER, Edgardo (Org). A colonialidade do saber: eurocentrismo e ciências sociais. Buenos Aires: CLACSO, 2005.

REVEL, Judith. Le vocabulaire de Foucault. Paris: Elipses edições, 2009.

SCHERER-WARREN, Ilse. Redes de movimentos sociais na América Latina: caminhos para uma política emancipatória? Caderno CRH, Salvador, v. 1, n. 54, p. 505-517, 2008.

SCOTT, James C. Formas cotidianas da resistência camponesa. Raízes, Campina Grande, v. 21, n. 1, p. 10-31, 2002.

SOUZA, Roberto Martins de. Na luta pela terra, nascemos faxinalenses: uma reinterpretação do campo intelectual de debates sobre os faxinais. Tese (Doutorado em Sociologia) - Universidade Federal do Paraná, Curitiba, 2010.

STENGERS, Isabelle. Au temps des catastrophes: resister à la barbarie qui vient. Paris: Éditions la Découverte, 2013.

TROUILLOT, Michel-Rolph. Silenciando o passado: poder e a produção da história. Curitiba: Huya, 2016.

VILLALOBOS, Jorge Ulisses Guerra; ROSSATO, Geovanio. A Comissão Pastoral da Terra (CPT): notas da sua atuação no Estado do Paraná. Boletim de Geografia, Maringá, v. 1, p. 19-31, 1996.

WEDIG, Josiane Carine. Organização política e luta pela diferença: ações coletivas da rede puxirão de povos e comunidades tradicionais. RURIS - Revista do Centro de Estudos Rurais - UNICAMP, v. 10, n. 1, p. 255-284, 2016.

WEDIG, Josiane Carine. Rede Puxirão de Povos e Comunidades Tradicionais do Paraná: luta pelo território e pela diferença. Tese (Doutorado em Ciências Sociais em Desenvolvimento, Agricultura e Sociedade) - Universidade Federal Rural do Rio de Janeiro, Rio de Janeiro, 2015. 